\title{
Determination of left ventricular wall thickness and muscle mass by intravenous digital subtraction angiocardiography: validation of the method
}

\author{
D. Grob, O. M. Hess, E. Monrad, B. Birchler, J. Grimm and H. P. Krayenbuehl \\ Department of Medicine, Medical Policlinic, Cardiology, University Hospital, Zurich, Switzerland
}

KEY WORDS: Digital subtraction angiography, left ventricular wall thickness, left ventricular muscle mass, conventional angiocardiography, supine bicycle exercise.

Left ventricular ( $L V)$ wall thickness and muscle mass are important measures of LV hypertrophy. In 24 patients $L V$ end-diastolic wall thickness and muscle mass were determined ( $t$ wo observers) by digital subtraction angiocardiography (DSA) and conventional $L V$ angiocardiography ( $L V A)$. Wall thickness was determined over the anterolateral wall of the left ventricle according to the technique of Rackley (method 1) or by planimetry (method 2). Seventeen patients were studied at rest and seven during dynamic exercise. Wall thickness correlated well between LVA and DSA; the best correlations were obtained by a combined subtraction mode using either method 1 or 2 (method $1, \mathrm{r} \geqslant 0 \cdot 80 ;$ method $2, \mathrm{r} \geqslant 0 \cdot 75)$. The standarderror of estimate of the mean (SEE) was slightly lower for method $2(\leqslant 10 \%)$ than for method $1(\leqslant 13 \%)$. DSA significantly overestimated wall thickness by 5-7\% with method 1 and underestimated by $12-14 \%$ with method 2 . Muscle mass correlated well between LVA and DSA; the SEE was $\leqslant 15 \%$ for method 1 and $\leqslant 12 \%$ for method 2 . Overestimation of muscle mass by DSA was $7-11 \%$ with method 1 and underestimation was $13-15 \%$ with method 2.

It is concluded that $L V$ wall thickness can be determined accurately by DSA with an SEE ranging between 10 and $13 \%$. Determination of $\mathrm{LV}$ muscle mass is slightly less accurate and the SEE is slightly larger ranging between 13 to $17 \%$. With method 1 , wall thickness and muscle mass were over estimated and with method 2 underestimated.

\section{Introduction}

Left ventricular $\mathrm{LV}$ wall thickness and muscle mass are important measures of LV hypertrophy. Determination of LV wall thickness can be performed by several non-invasive techniques such as echocardiography, computer tomography or magnetic resonance ${ }^{[1-5]}$. As most of these techniques do not allow accurate wall thickness measurements at rest and during exercise, angiocardiographic methods ${ }^{[6]}$ are often used for assessment of $\mathrm{LV}$ wall thickness and muscle mass ${ }^{[7,8]}$. The purpose of the present study was to evaluate the accuracy of digital subtraction angiocardiography for determination of L V end-diastolic wall thickness and muscle mass at rest and during bicycle exercise. Three different

Submitted for publication on 27 January 1987 and in revised form 22 June 1987.

Address for correspondence: Oto M. Hess, M.D., Medical Policlinic, Cardiology, Unversity Hospital, Raemistrasse 100, CH-8091 Zunich, Switzerland. subtraction modes ${ }^{[9]}$ and two different methods for LV wall thickness determination were tested and the results were compared to wall thickness and muscle mass data obtained from conventional LV angiocardiography. Conventional cinefilm was used as a data carrier for digital subtraction angiography to guarantee high temporal and spatial resolution which is especially important during bicycle exercise.

\section{Patients and methods}

Twenty-five patients (22 male, 3 female; $27-64$ years of age, mean 51 years) who underwent cardiac catheterization for routine diagnostic purposes were included in the present study. These patients were selected from a previous study on the comparison of digital subtraction angiocardiography with conventional contrast ventriculography ${ }^{\{9]}$. Coronary artery disease was diagnosed in 24 patients. One patient had normal coronary arteries. One of the 25 patients had to be excluded for technical reasons. 
Seventeen of the 24 patients with coronary artery disease had a history of myocardial infarction (one posterior, six infenor, seven anterior and three infarctions which could not be localized in the ECG).

The patients at rest had first conventional left ventricular cineangiocardiography in the right anterior oblique projection (RAO) with injection of $45 \mathrm{ml}$ Urographin $76 \%\left(12 \mathrm{ml} \mathrm{s}^{-1}\right)$ into the left ventricle with a $8 \mathrm{~F}$-pigtail catheter. The angiocardiogram was recorded on cinefilm by means of a Siemens Angioscope system at a frame rate of 50 frames $\mathrm{s}^{-1}$. Simultaneously, a standard lead of the ECG and a numerical code which also appeared on the cinefilm were recorded on an oscillograph (Electronics for Medicine VR 12) at a paper speed of $250 \mathrm{~mm} \mathrm{~s}^{-1}$. After the first angiogram, an interval of $15 \mathrm{~min}$ was allowed for dissipation of the hemodynamic effects of the contrast agent. Then, a second injection of $45 \mathrm{ml}$ Urographin $\left(15 \mathrm{ml} \mathrm{s}^{-1}\right)$ was performed into the superior vena cava. The entire sequence starting one or two heart cycles before the injection and ending after the contrast agent had passed through the left ventricle was recorded on cinefilm at the same frame rate of 50 frames $\mathrm{s}^{-1}$. During the passage of the contrast agent from the vena cava to the left ventricle, the patients were asked to stop breathing to avoid misregistration from patient motion.

Seven patients were studied during bicycle exercise at a mean workload of $55 \mathrm{~W}$ (range 50-75 W) for $2 \mathrm{~min}$. The exercise test was carried out at a low or a moderate workload because it had to be performed twice and the patients had to stop breathing. At the end of the exercise period, conventional RAO LV cineangiocardiography was carried out first by injection of $60 \mathrm{ml}$ Urographin $76 \%$ into the left ventricle with a flow rate of $16-18 \mathrm{ml} \mathrm{s}^{-1}$. After the first angiogram, an interval of $15 \mathrm{~min}$ was allowed for dissipation of the hemodynamic effects of the contrast agent. Then, the bicycle exercise test was repeated at the same workload and duration as before and $60 \mathrm{ml}$ Urographin $76 \%$ (flow rate $16-18 \mathrm{ml} \mathrm{s}^{-1}$ ) were injected into the superior vena cava. No patient experienced angına pectoris during the exercise test.

At the end of the procedure, a metal sphere of known diameter $(6 \mathrm{~cm})$ was filmed to correct for radiographic magnification and pincushion distortion.

\section{DIGITAL IMAGE PROCESSING}

The cinefilm was scanned on a computer-assisted
(VAX 750) image processing system with a modified Vanguard XR-35 film-projector and a high resolution photodiode camera (Eikonıx 78/99). The observer entered the numbers of the desired frames for digitization at the computer terminal. The cinefilm was transported automatically under computer control. Individual image points were digitized with 12-bit resolution and stored on disk, averaged and subtracted on an image processor with $512 \times 512$ pixels resolution. Two to four frames were usually digitized and a veraged to reduce image noise. From the averaged image the mask was subtracted to increase image contrast. After subtraction, the image was linearly amplified to extend the brightness over the whole dynamic range of the image processing system $^{[9]}$.

Three different subtraction modes were tested to determine the most accurate technique for left ventricular mass determination with conventional angiocardiograms as the reference method ${ }^{[9]}$.

\section{MASK MODE SUBTRACTION (MMS)}

The subtraction mask was usually taken before the agent was injected into the patient at the beginning of the film sequence ${ }^{[9-11]}$. In certain patients the mask was taken at the end of the film sequence when the contrast agent had passed the left ventricle because of movement between the initial lung passage and the contrast sequence (Fig. 1).

\section{TIME INTER VAL DIFFERENCE (TID)}

Time interval difference imaging was based on the same algorithm as the mask mode subtraction except that the time between the mask and the opacified image was very short ${ }^{[9.12]}$, in the range of 60-100 ms (Fig. 1). As a result, rapidly moving objects are visualized accurately in the TID mode whereas stationary and slowly moving parts are subtracted and hence not seen. TID images were usually less noisy than MMS images because averaging of multiple frames did not have to be performed.

\section{MMS AND TID MODE (COMBINED METHOD)}

A combined method which allowed sequential superimposition of MMS and TID images was used $^{[9]}$ to take advantage of the relative imaging strengths of each method (e.g. the TID mode was used to determine the rapidly moving sections of the LV wall and MMS was used to detect the slowly moving parts of the wall) (Fig. 1). 


\section{LVA}

\section{DSA}

MMS
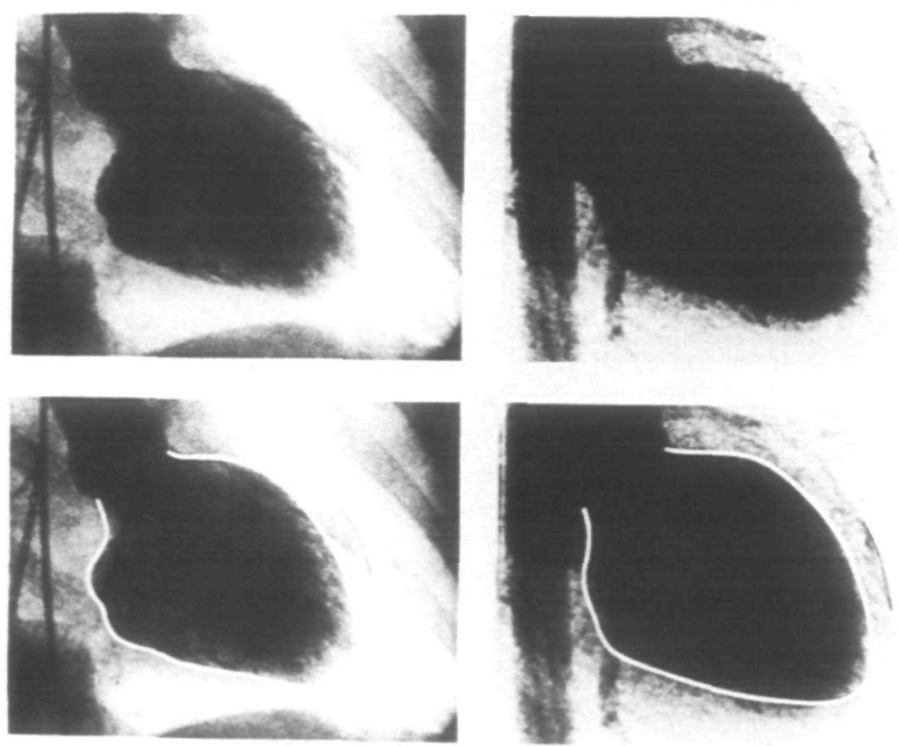

TID
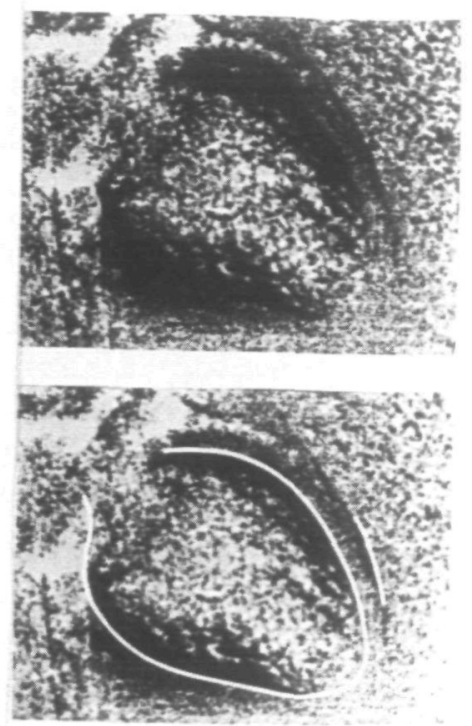

Figure I Conventional (LVA: left). mask mode (MMS; middle) and time interval difference (TID; right) subtracted angiograms. The upper panels show the end-diastolic silhouettes as they are displayed on the video monitor and the lower panels show the silhouettes after completion of the contour detection. The left ventricular wall thickness can be identified in all three images at the anterolateral region of the left ventricle.

CONTOUR DETECTION AND VOLUME CALCULATION

Contour detection and $\mathrm{LV}$ volume determination have been described previously ${ }^{[9]}$. In the meantime, the system has been adapted for LV wall thickness and muscle mass determination. The silhouette was traced by a semi-automatic contour detection algorithm on the high-resolution monitor. As noise and motion artifacts often lead to poor image quality, a fully automatic contour detection of the ventricle was not used. Boundary detection was performed on the monitor using a 'mouse' controlled cursor. Two observers selected a variable number of boundary points which were connected by a cubic spline function ${ }^{[9]}$. Usually, a set of 10-15 points resulted in an acceptable definition of the LV contour. This method was used for MMS, TID and, in an extended implementation, also for the combined MMS and TID method. In the combined subtraction mode, the LV contour was determined by the
MMS image alternating with the TID image which was exactly superimposed over the MMS image with retention of previously selected boundary points. According to Rackley and coworkers ${ }^{[16]} \mathrm{LV}$ wall contour was delineated at the lateral edge of the RAO cardiac silhouette and its average thickness was determined using two different methods(Fig. 1):

method 1: LV end-diastolic wall thickness was determined according to the technique of Rackley using the average wall thickness of multiple wall diameters which were inscribed orthogonally to the epicardial border;

method 2: LV end-diastolic wall thickness was determined by planimetry of the wall segment dividing the wall area by its midwall length.

Wall thickness can be delineated due to the fact 


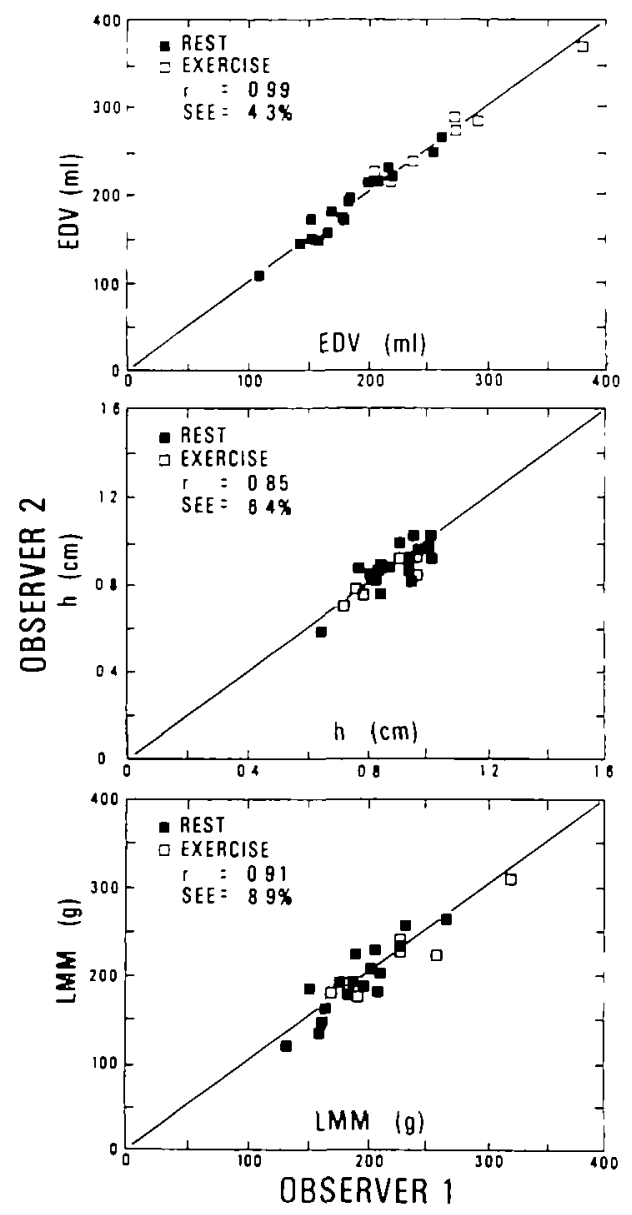

Figure 2 Interobserver comparison for end-diastolic volume (EDV, upper panel), LV end-diastolic wall thıckness (h, middle panel) and LV muscle mass (LMM, lower panel) using conventional anglocardiography. All three parameters show an excellent correlation between the two observers with a standard error of estumate of the mean (SEE) smaller than $10 \%$.

that the myocardium is already opacified at the time of digitisation, otherwise it would have been subtracted.

LV volume was calculated using the "area-length" method for monoplane angiograms $s^{[13]}$ and left ventricular muscle mass (LMM) was calculated according to Rackley and coworkers ${ }^{[\hat{[}]}$ as follows:

$$
\operatorname{LMM}=1 \cdot 05\left\{\left[(4 \pi / 3)(\mathrm{L} / 2+\mathrm{h})(\mathrm{D} / 2+\mathrm{h})^{2}\right]-\right.
$$

where $\mathrm{L}$ is the $\mathrm{LV}$ end-diastolic long axis in the RAO view, D is the LV end-diastolic short axis in the RAO view calculated according to the 'arealength' method ${ }^{\mid 13]}, h$ is the LV end-diastolic wall thickness. LVEDV is the LV end-diastolic volume, and $1.05 \mathrm{~g} \mathrm{ml}^{-1}$ the specific gravity of heart muscle. All parameters were determined by two independent observers from conventional angiograms as well as from digital angiograms using the MMS, TID and MMS + TID techniques. The correlations for LV end-diastolic volume, LV end-diastolic wall thickness and LV muscle mass (Fig. 2) were excellent between the two observers using conventional angiocardiography.

\section{STATISTICAL METHODS}

Data obtained by digital subtraction angiocardiography and LV angiocardiography were compared by a parred Student's $t$-test; rest and exercise data were compared by an unpaired Student's $t$-test.

A linear regression analysis was used to compare data obtained by digital subtraction and conventional LV angiocardiography. The line of identity is indicated in all the Figures and the correlation coefficient $(r)$ and the standard error of estimate (SEE) were calculated for both observers and all comparisons. The mean difference (d) and the standard deviation of the mean difference were calculated according to the technique of Bland and Altman ${ }^{[14]}$. It was found that the standard deviation of the mean difference and the standard error of estimate of the regression analysis are very similar with only small variations. The correlation between these two measures was very good with a correlation coefficient of 0.92 for $L V$ volume, 0.91 for wall thickness, and 0.96 for muscle mass determination. This observation can be explained by the fact that the mean difference between two measurements (d) and the residuals between the observed data and the calculated regression line (standard error of estimate) are almost identical when the slope of the regression line between two variables (digital subtraction angiocardiography vs. LV anglocardiography) is close to 1 . Thus, only standard errors of estimate are reported in the present paper.

In all the Figures and Tables, mean \pm 1 standard deviation are given.

\section{Results}

Conventional and digitally subtracted angiograms for wall thickness determination are shown in Fig. 1. The MMS and TID subtraction were used in the digital subtraction angiogram for delineation 
Table 1 Standard hemodynamic data

\begin{tabular}{|c|c|c|c|c|c|c|}
\hline & \multicolumn{3}{|c|}{ LVA } & \multicolumn{3}{|c|}{ DSA } \\
\hline & HR & LVEDP & LVSP & HR & LVEDP & LVSP \\
\hline \multicolumn{7}{|l|}{ Rest } \\
\hline Mean & 66 & 17 & 132 & 66 & 19 & 142 \\
\hline $\pm S D$ & 15 & 7 & 22 & 18 & 7 & 27 \\
\hline \multicolumn{7}{|l|}{ Exercise } \\
\hline Mean & 95 & 31 & 148 & 97 & 31 & 142 \\
\hline$\pm \mathrm{SD}$ & 8 & 7 & 10 & 12 & 9 & 20 \\
\hline$P($ rest vs. ex. $)$ & $<0.001$ & $<0001$ & NS & $<0.001$ & $<0.005$ & NS \\
\hline
\end{tabular}

LVA, left ventricular angiocardiography; DSA, digital subtraction angiocardiography; HR, heart rate (bpm); LVEDP, left ventricular end-diastolic pressure (mmHg); LVSP, left ventricular peak systolic pressure $(\mathrm{mmHg}) ; \mathrm{SD}$, standard deviation; ex, exercise; $P$, probability; NS, not significant.

Table 2 Left ventricular angiocardiography versus digital subtraction anglocardiography (method 1)

\begin{tabular}{|c|c|c|c|c|c|c|c|c|c|c|}
\hline & \multirow{2}{*}{\multicolumn{3}{|c|}{ LVA }} & \multicolumn{7}{|c|}{$\mathrm{DSA}$} \\
\hline & & & & \multirow[b]{2}{*}{ EDV } & \multicolumn{2}{|c|}{ MMS } & \multicolumn{2}{|c|}{ TID } & \multicolumn{2}{|c|}{ MMS + TID } \\
\hline & EDV & $\mathrm{h}$ & LMM & & $\mathrm{h}$ & LMM & h & LMM & h & LMM \\
\hline \multicolumn{11}{|l|}{$\begin{array}{l}\text { Rest } \\
\text { OB } 1\end{array}$} \\
\hline Mean & 185 & 0.87 & 189 & 198 & 0.97 & 220 & 0.93 & 228 & 0.94 & 218 \\
\hline$\pm \mathrm{SD}$ & 39 & 0.12 & 40 & 35 & $0 \cdot 17$ & 49 & $0 \cdot 15$ & 59 & $0 \cdot 18$ & 56 \\
\hline \multicolumn{11}{|l|}{ OB 2} \\
\hline Mean & 189 & 0.89 & 194 & 196 & 0.91 & 201 & 0.90 & 203 & 0.93 & 211 \\
\hline$\pm \mathrm{SD}$ & 40 & 0.11 & 39 & 35 & $0 \cdot 13$ & 37 & 0.17 & 55 & $0 \cdot 14$ & 49 \\
\hline \multicolumn{11}{|l|}{ Exercise } \\
\hline \multicolumn{11}{|l|}{ OB 1} \\
\hline Mean & 268 & 0.84 & 226 & 255 & 0.98 & 248 & 0.88 & 244 & 0.89 & 231 \\
\hline$\pm \mathrm{SD}$ & 58 & $0 \cdot 13$ & 60 & 63 & $0 \cdot 14$ & 49 & 015 & 59 & 0.12 & 59 \\
\hline \multicolumn{11}{|l|}{ OB 2} \\
\hline Mean & 272 & 0.82 & 219 & 256 & 0.95 & 253 & 0.88 & 233 & 0.87 & 228 \\
\hline$\pm \mathrm{SD}$ & 52 & 0.09 & 47 & 48 & $0 \cdot 10$ & 54 & $0 \cdot 12$ & 57 & $0 \cdot 13$ & 53 \\
\hline \multicolumn{11}{|c|}{$P($ rest vs.ex.) } \\
\hline OB I & $<0.001$ & NS & NS & $<0.01$ & NS & NS & NS & NS & NS & NS \\
\hline OB 2 & $<0.001$ & NS & NS & $<0.01$ & NS & NS & NS & NS & NS & NS \\
\hline \multicolumn{11}{|c|}{$\mathrm{P}(O B /$ vs. $O B 2 ; n=24)$} \\
\hline & NS & NS & NS & NS & $<0.05$ & NS & NS & NS & NS & NS \\
\hline \multicolumn{11}{|c|}{$\mathrm{P}(L V A$ vs. $D S A ; n=24)$} \\
\hline OB 1 & & & & NS & $<0.005$ & $<0.001$ & NS & $<0.05$ & $<0.005$ & $<0.005$ \\
\hline OB 2 & & & & NS & NS & $<0.050$ & NS & NS & $<0.020$ & $<0010$ \\
\hline
\end{tabular}

MMS, mask mode subtraction; TID, time interval difference subtraction; EDV, end-diastolic volume (ml); h, end-diastolic wall thickness (cm); LMM, left ventricular muscle mass (g); OB, observer; other abbreviations are as in Table 1 . 
Table 3 Left ventricular angiocardiography and digital subtraction angiocardiography (method 2)

\begin{tabular}{|c|c|c|c|c|c|c|c|c|}
\hline & \multirow{2}{*}{\multicolumn{2}{|c|}{ LVA }} & \multicolumn{6}{|c|}{ DSA } \\
\hline & & & \multicolumn{2}{|c|}{ MMS } & \multicolumn{2}{|c|}{ TID } & \multicolumn{2}{|c|}{ MMS + TID } \\
\hline & $\mathrm{h}$ & LMM & h & LMM & $\mathrm{h}$ & LMM & h & LMM \\
\hline \multicolumn{9}{|l|}{ Rest } \\
\hline \multicolumn{9}{|l|}{ OB 1} \\
\hline Mean & 089 & 190 & 0.81 & 174 & 0.76 & 164 & 0.78 & 170 \\
\hline $\pm S D$ & $0 \cdot 10$ & 33 & $0 \cdot 14$ & 38 & $0 \cdot 11$ & 37 & $0 \cdot 13$ & 41 \\
\hline \multicolumn{9}{|l|}{ OB 2} \\
\hline Mean & 0.89 & 193 & 0.75 & 191 & 0.72 & 158 & 0.76 & 164 \\
\hline $\pm S D$ & 0.11 & 39 & $0 \cdot 12$ & 35 & $0 \cdot 13$ & 40 & $0 \cdot 12$ & 37 \\
\hline \multicolumn{9}{|l|}{ Exercise } \\
\hline \multicolumn{9}{|l|}{ OB 1} \\
\hline Mean & 0.84 & 226 & 083 & 189 & 0.73 & 197 & 0.73 & 184 \\
\hline $\pm S D$ & $0 \cdot 10$ & 51 & $0 \cdot 10$ & 35 & 0.12 & 50 & 0.08 & 45 \\
\hline \multicolumn{9}{|l|}{ OB 2} \\
\hline Mean & 0.82 & 219 & 0.79 & 203 & 0.77 & 185 & 0.72 & 182 \\
\hline $\pm S D$ & 0.08 & 47 & 0.08 & 42 & 0.11 & 47 & $0 \cdot 10$ & 43 \\
\hline \multicolumn{9}{|c|}{$\mathrm{P}$ (rest vs.ex.) } \\
\hline OB 1 & NS & NS & NS & NS & NS & NS & NS & NS \\
\hline OB 2 & NS & NS & NS & NS & NS & NS & NS & NS \\
\hline \multicolumn{9}{|c|}{$\mathrm{P}(O B /$ vs. $O B 2 ; n=24)$} \\
\hline & NS & NS & $<0.020$ & NS & NS & NS & NS & NS \\
\hline \multicolumn{9}{|c|}{$\mathrm{P}(L V A$ vs $D S A ; n=24)$} \\
\hline OB 1 & & & $<0.050$ & $<0.010$ & $<0.001$ & $<0.005$ & $<0.001$ & $<0.001$ \\
\hline OB 2 & & & $<0.001$ & $<0.001$ & $<0-001$ & $<0.001$ & $<0.001$ & $<0.001$ \\
\hline
\end{tabular}

Abbreviations as in Table $\mathrm{l}$ and 2.

of $L V$ wall thickness. The TID image allows a better delineation of the endo- and epicardial border of LV wall thickness than the MMS image due to its better resolution.

\section{HEMODYNAMIC MEASUREMENTS}

Heart rate, LV end-diastolic and peak systolic pressure were similar during conventional and digital subtraction anglocardiography at rest and during exercise (Table 1). Heart rate and LV enddiastolic pressure were significantly higher during exercise than at rest.

COMPARISON OF LV ANGIOCARDIOGRAPHIC DATA. LVA VERSUS DSA

Data for method 1 are given in Table 2 and for method 2 in Table 3.

\section{Method I}

$L V$ volume. LV end-diastolic volume was not significantly different at rest and during exercise
Tahle 4 Correlation coefficients ( $\mathbf{r}$ ) and standard error of the mean ( $S E E$ ) for $L V$ volume delermination

\begin{tabular}{|c|c|c|c|c|}
\hline & & $r$ & $P$ & $\operatorname{SEE}(\%)$ \\
\hline \multicolumn{5}{|c|}{ (a) $L V A$ vs. $D S A(n=24)$} \\
\hline \multirow[t]{2}{*}{ OB I } & Rest & 0.93 & $<0.001$ & 7 \\
\hline & Exercise & 0.99 & $<0001$ & 4 \\
\hline & All & 0.96 & $<0001$ & 7 \\
\hline \multirow[t]{3}{*}{$\mathrm{OB} 2$} & Rest & 0.92 & $<0.001$ & 8 \\
\hline & Exercise & 098 & $<0.001$ & 4 \\
\hline & All & 096 & $<0.001$ & 6 \\
\hline \multicolumn{5}{|c|}{$\begin{array}{l}\text { (b) } O B / \text { vs. } O B 2(n=24) \\
E D V\end{array}$} \\
\hline \multirow{3}{*}{$E D V_{\text {LVA }}$} & Rest & 0.98 & $<0.001$ & 5 \\
\hline & Exercise & 0.99 & $<0.001$ & 4 \\
\hline & All & 0.99 & $<0.001$ & 4 \\
\hline \multicolumn{5}{|c|}{$E D V_{\text {OSA }}(M M S+T I D)$} \\
\hline & Rest & 0.98 & $<0.001$ & 4 \\
\hline & Exercise & 0.99 & $<0.001$ & 3 \\
\hline & All & 0.98 & $<0.001$ & 5 \\
\hline
\end{tabular}

Abbreviations are as in Tables 1 and 2. 
between conventional and digital subtraction angiocardiography. $\mathrm{LV}$ end-diastolic volume was overestimated by $4-7 \%(P<0.02)$ at rest but underestimated by $5-6 \% \quad(P<0.001)$ during exercise using digital subtraction angiocardiography.

$L V$ wall thickness and muscle mass. $\mathrm{LV}$ wall thickness and muscle mass were systematically overestimated at rest and during exercise by digital subtraction angiocardiography with MMS, TID and MMS + TID subtraction when compared to conventional angiocardiography. In two patients, neither observer was able to trace $\mathrm{LV}$ wall thickness

Table 5 Correlation coefficients ( $\mathrm{r}$ ) and standard error of estumate of the mean (SEE) for LV wall thickness and muscle mass determination ( $L V A$ vs DSA): methods 1 and 2

\begin{tabular}{|c|c|c|c|c|c|c|c|}
\hline & & \multicolumn{3}{|c|}{ Method 1} & \multicolumn{3}{|c|}{ Method 2} \\
\hline & & $r$ & $P$ & $\operatorname{SEE}(\%)$ & $r$ & $P$ & $\operatorname{SEE}(\%)$ \\
\hline \multicolumn{8}{|c|}{$\mathrm{h}_{\mathrm{LVA}}$ vs. $\mathrm{h}_{\text {MNS }}(n=22)$} \\
\hline \multirow[t]{3}{*}{ OB 1} & Rest & 0.72 & $<0.005$ & 14 & 0.69 & $<0.005$ & 12 \\
\hline & Ex. & 0.05 & NS & 19 & 0.25 & NS & 13 \\
\hline & All & 0.49 & $<0.025$ & 12 & 0.44 & $<0.050$ & 14 \\
\hline \multirow[t]{3}{*}{$\mathrm{OB} 2$} & Rest & 0.66 & $<0.010$ & 11 & 0.52 & $<0.050$ & 12 \\
\hline & $\mathrm{Ex}$ & $0 \cdot 14$ & NS & 13 & 0.05 & NS & 11 \\
\hline & All & 0.84 & $<0-025$ & 12 & $0 \cdot 34$ & NS & 12 \\
\hline \multicolumn{8}{|c|}{$\mathrm{h}_{\mathrm{LVA}}$ vs. $\mathrm{h}_{\mathrm{TID}}(n=24)$} \\
\hline \multirow[t]{3}{*}{ OB I } & Rest & 0.64 & $<0.010$ & 13 & 0.59 & $<0.020$ & 11 \\
\hline & Ex. & 0.42 & NS & 18 & 0.44 & NS & 14 \\
\hline & All & 0.59 & $<0.050$ & 14 & 0.55 & $<0.005$ & 11 \\
\hline \multirow[t]{3}{*}{ OB 2} & Rest & $0 \cdot 60$ & $<0.020$ & 16 & 0.47 & NS & 14 \\
\hline & Ex. & 0.63 & NS & 12 & 0.61 & $<0.005$ & 5 \\
\hline & All & 0.59 & $<0.050$ & 15 & 0.55 & $<0.010$ & 12 \\
\hline \multicolumn{8}{|c|}{$\mathrm{h}_{\mathrm{LVA}}$ vs. $\mathrm{h}_{\text {MMS }+ \text { TID }}(n=24)$} \\
\hline \multirow[t]{3}{*}{ OB 1} & Rest & 0.79 & $<0.001$ & 13 & 0.80 & $<0-001$ & 9 \\
\hline & Ex. & 0.86 & $<0.020$ & 8 & 0.85 & $<0.020$ & 6 \\
\hline & All & 0.84 & $<0.001$ & 10 & 0.81 & $<0.001$ & 8 \\
\hline \multirow[t]{3}{*}{ OB 2} & Rest & 0.83 & $<0.001$ & 9 & 0.76 & $<0-001$ & 9 \\
\hline & Ex. & 0.66 & NS & 13 & 0.68 & NS & 10 \\
\hline & All & $0 \cdot 80$ & $<0.001$ & 10 & 0.75 & $<0.00 \mathrm{l}$ & 9 \\
\hline \multicolumn{8}{|c|}{$\mathrm{LMM}_{\mathrm{LVA}}$ vs. $\mathrm{LMM}_{\mathrm{Mus}}(n=22)$} \\
\hline \multirow[t]{3}{*}{ OB 1} & Rest & 0.76 & $<0.005$ & 18 & 0.75 & $<0.005$ & 14 \\
\hline & Ex. & 0.60 & NS & 19 & 0.69 & NS & 12 \\
\hline & All & 0.69 & $<0-001$ & 19 & 0.72 & $<0.001$ & 13 \\
\hline \multirow[t]{3}{*}{ OB 2} & Rest & $0 \cdot 71$ & $<0.005$ & 14 & 0.62 & $<0.020$ & 14 \\
\hline & Ex. & 0.65 & NS & 20 & 0.60 & NS & 17 \\
\hline & All & $0 \cdot 72$ & $<0.001$ & 17 & $0 \cdot 66$ & $<0.001$ & 16 \\
\hline \multicolumn{8}{|c|}{$\mathrm{LMM}_{\mathrm{LVA}}$ vs. $\operatorname{LMM}_{\mathrm{TID}}(n=24)$} \\
\hline \multirow[t]{3}{*}{ OB 1} & Rest & 0.56 & $<0.020$ & 25 & $0 \cdot 70$ & $<0.005$ & 14 \\
\hline & Ex. & 0.84 & $<0.020$ & 15 & 0.28 & NS & 23 \\
\hline & All & 0.63 & $<0.005$ & 22 & 0.58 & $<0.005$ & 18 \\
\hline \multirow[t]{3}{*}{ OB 2} & Rest & 0.72 & $<0.005$ & 20 & 0.66 & $<0.005$ & 16 \\
\hline & Ex. & 0.82 & $<0-050$ & 17 & 0.88 & $<0.010$ & 11 \\
\hline & All & 0.77 & $<0.001$ & 18 & 0.76 & $<0.001$ & 14 \\
\hline \multicolumn{8}{|c|}{$\mathrm{LMM}_{\mathrm{LVA}}$ vs. $\mathrm{LMM}_{\mathrm{MNS}+\mathrm{TD}}(n=24)$} \\
\hline \multirow[t]{3}{*}{ OB I } & Rest & 0.85 & $<0.001$ & 16 & 0.83 & $<0.001$ & 12 \\
\hline & Ex. & 0.93 & $<0.005$ & 11 & 0.93 & $<0.005$ & 7 \\
\hline & All. & 0.85 & $<0.001$ & 15 & 0.83 & $<0-001$ & 12 \\
\hline \multirow[t]{3}{*}{$\mathrm{OB} 1$} & Rest & 0.91 & $<0.001$ & 11 & 0.84 & $<0-001$ & 11 \\
\hline & Ex. & 0.77 & $<0.050$ & 17 & 0.80 & $<0.050$ & 13 \\
\hline & All & 0.86 & $<0.001$ & 13 & 0.83 & $<0-001$ & 11 \\
\hline
\end{tabular}



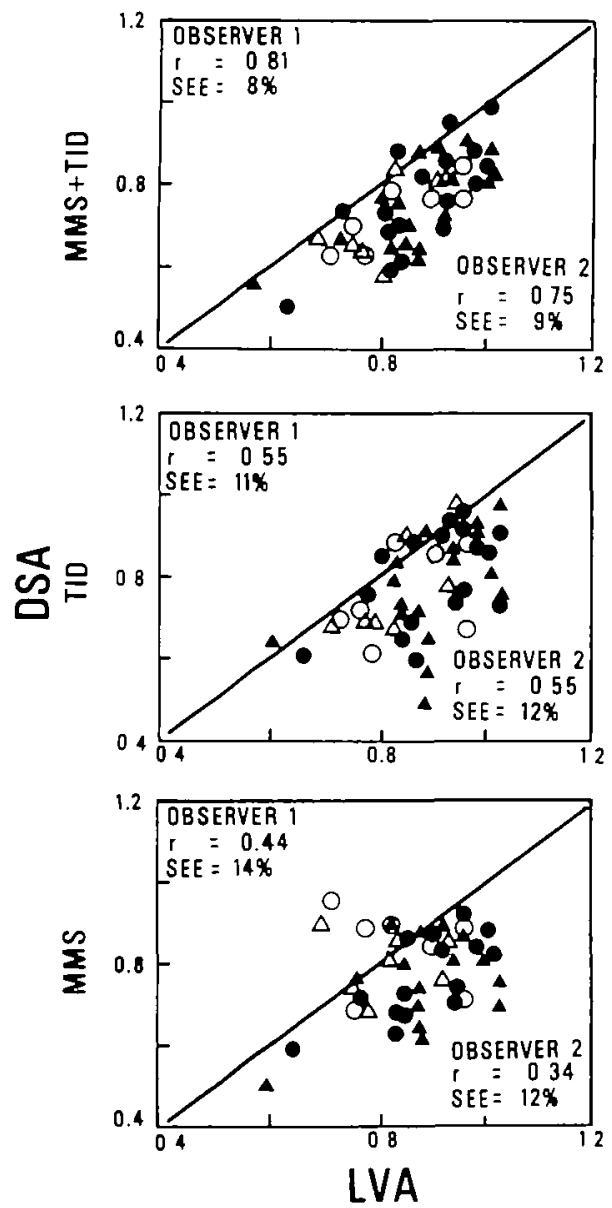

Figure 3 Intraobserver comparisons for LV end-diastolic wall thickness $(\mathrm{cm})$ between digital subtraction (DSA; ordinate) and conventional LV angiocardiography (LVA; abscissa). Correlation coefficient $(r)$ and standard error of estimate of the mean (SEE) are given separately for observer 1 $(\odot$, rest; $O$, exercise) and $2(\Delta$, rest; $\Delta$, exercise) with mask mode (MMS; lower panel), time-interval difference (TID; middle panel) and combined subtraction (MMS + TID; upper panel) using method 2. The best correlations were observed for the combined subtraction mode with standard errors of 8 and $9 \%$ (of LVA wall thickness), respectively.

using MMS subtraction due to low-contrast images. LV wall thickness was overestimated by $5-7 \%$ $(P<0.02)$ and $\mathrm{LV}$ muscle mass by $7-11 \%(P<0.01)$ using digital subtraction angiocardiography (MMS + TID subtraction).

\section{Method 2}

LV wall thickness and muscle mass. LV wall thickness and muscle mass were systematically underestimated at rest and during exercise by digital subtraction angiocardiography with MMS, TID and MMS + TID subtraction when compared to conventional angiocardiography. Underestimation was $12-14 \% \quad(P<0.001)$ for LV wall thickness (MMS + TID subtraction) and 13-15\% $(P<0.001)$ for LV muscle mass (MMS + TID subtraction).
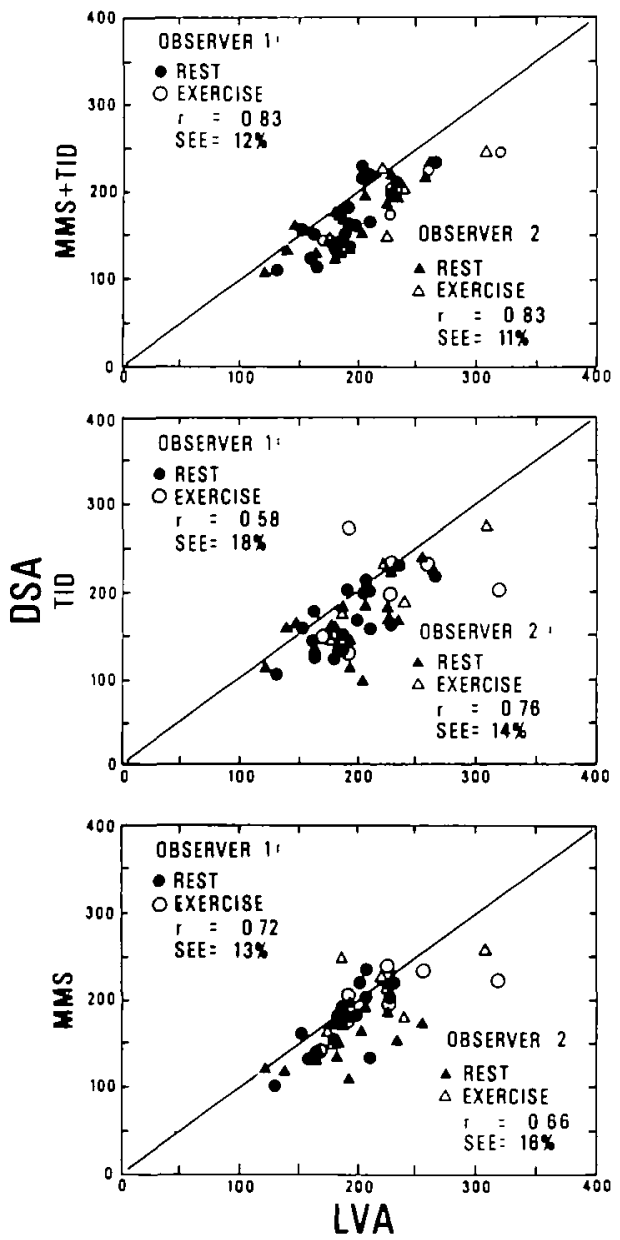

Figure 4 Intraobserver comparisons for LV muscle mass (g) between digital subtraction (DSA; ordinate) and conventional LV angiocardiography (LVA; abscissa). Correlation coefficient $(r)$ and standard error of estimate of the mean (SEE) are given for observers 1 and 2 with mask mode (MMS lower panel), time-interval difference (TID; middle panel) and combined subtraction (MMS + TID; upper panel) using method 2. The best correlations were observed for the combined subtraction mode with standard errors of 12 and $11 \%$ (of LVA muscie mass), respectively. 

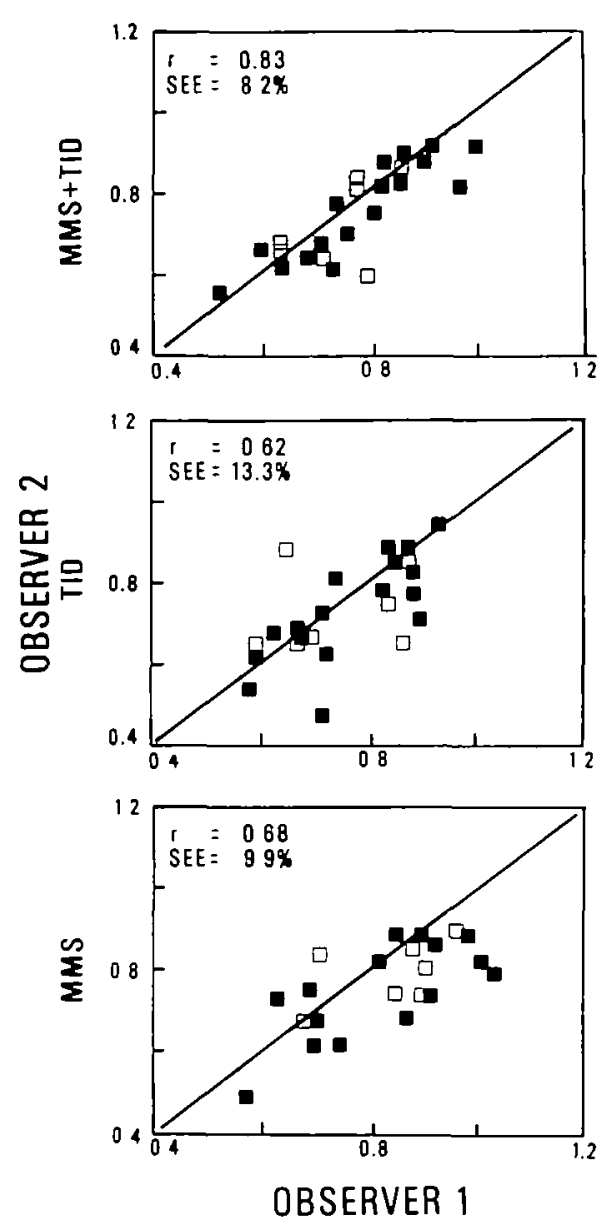

Figure 5 Interobserver companson for LV end-diastolic wall thickness $(\mathrm{cm})$ using digital subtraction angiocardiography (DSA). Correlation coefficient ( $r$ ) and standard error of estimate of the mean (SEE) are given for mask mode (MMS; lower panel), time interval difference (TID; middle panel) and combined subtraction (MMS + TID; upper panel) using method 2. The best correlation is observed with the combined subtraction mode; the SEE amounting to $8 \%$. D, Rest; $\square$, Exercise.

\section{INTRA- AND INTEROBSER VER COMPARISON OF LV}

END-DIASTOLIC VOLUME; LVA VERSUS DSA

High correlation coefficients $(\geqslant 0.92)$ with a small standard error of estimate of the mean $(\leqslant 8 \%)$ were found for both observers between conventional and digital angiocardiography (Table 4). Interobserver data also showed high correlation coefficients $(\geqslant 0.98)$ with a small standard error of estimate of the mean $(\leqslant 5 \%)$ for both conventional and digital subtraction angiocardiography (Table 4).
INTRAOBSER VER COMPARISON FOR LV WALL THICKNESS AND MUSCLE MASS; LVA VERSUS DSA

Both methods showed similar results for $L V$ wall thickness and muscle mass determination by LV angiocardiography and digital subtraction angiocardiography (Table 5, Figs 3 and 4). Method 2 showed similar correlations but smaller standard errors of estimate of the mean than method 1 . The correlations between conventional and digital subtraction angiocardiography were similar for rest and exercise data but the best correlations were observed with the combined subtraction technique (MMS + TID) for both wall thickness (Fig. 3) and muscle mass (Fig. 4). The lowest correlations were shown with the mask mode subtraction (MMS) followed by the time interval difference subtraction (TID). The smallest standard error of estimate of the mean was observed with method 2 using the combined subtraction mode: the error was $\leqslant 10 \%$ for wall thickness and $\leqslant 13 \%$ for muscle mass determination (Figs 3 and 4).

INTEROBSER VER COMPARISONS FOR LV VOLUME, WALL THICKNESS AND MUSCLE MASs; Table $4 b$ and 6 , Figs 2 and 5

Correlation coefficients and standard errors of estimate of the mean were excellent for interobserver comparison of LV volume, wall thickness and muscle mass (Fig. 2) using conventional angiocardiography. Interobserver comparison of LV wall thickness using digital subtraction angiocardiography (Fig. 5) showed good correlations for mask mode subtraction (MMS) and combined subtraction (MMS + TID) with a standard error of estimate of the mean of less than $10 \%$. The correlation between the two observers was slightly less good for time-interval difference (TID) subtraction. Similar data were observed for $\mathrm{LV}$ muscle mass (Table 6) although the standard error of estimate of the mean was generally higher than for LV wall thickness. There was no differences in correlation coefficients for method $\mathrm{I}$ or 2 and for data at rest and during exercise, although the agreement of the data during exercise tended to be less good than that of the data recorded at rest.

\section{Discussion}

LV wall thickness and muscle mass have been used for the assessment of LV hypertrophy in different forms of cardiac disease ${ }^{[7,8,15]}$. Severe myocardial hypertrophy has been shown to be associated with a poor postoperative outcome in patients with 
chronic pressure and volume overload due to aortic valve disease $\mathrm{f}^{[15-18]}$. Thus, LV wall thickness and muscle mass are important determinants for postoperative outcome and prognosis in patients with valvular heart disease $e^{[16]}$. Several methods have been used for the assessment of LV wall thickness and muscle mass including several non-invasive (echocardiography, computer tomography and magnetic resonance $\left.{ }^{[1-4,15,19-23]}\right)$ and invasive techniques (angiocardiography and digital subtraction angiocardiography $y^{[6,9,24)}$. Angiocardiography has been, and is still, the reference method for assessing myocardial muscle mass in $\operatorname{man}^{[6]}$. It has been shown that angiocardiography provides excellent correlation with post-mortem determinations of muscle mass ${ }^{[0,25]}$. Similar correlation can be obtained with magnetic resonance ${ }^{[4]}$ due to its high resolution and good structural recognition capabilities $^{[19]}$. One limiting factor is, however, the long sampling time which renders the method especially sensitive to motion artifacts.

In the present study, we evaluated the accuracy of digital subtraction angiocardiography for the assessment of LV end-diastolic wall thickness and muscle mass not only at rest but also during supine bicycle exercise. Determination of LV wall thickness is important for calculation of $L V$ wall stress and stress-shortening relations to identify patients with resting or exercise-induced myocardial dysfunction. Furthermore, estimation of LV muscle mass from rest to exercise represents an easy and simple test for assessing the accuracy of muscle-mass

Table 6 Interobserver variability of $L V$ volume, wall thickness and muscle mass determination ( $O B /$ vs. $O B 2$ ): methods 1 and 2

\begin{tabular}{|c|c|c|c|c|c|c|}
\hline & \multicolumn{3}{|c|}{ Method 1} & \multicolumn{3}{|c|}{ Method 2} \\
\hline & $r$ & $P$ & SEE $(\%)$ & $r$ & $P$ & SEE $(\%)$ \\
\hline \multicolumn{7}{|c|}{$\mathrm{h}_{\mathrm{LVA}}(n=24)$} \\
\hline Rest & 0.88 & $<0.001$ & $6 \cdot 4$ & 0.85 & $<0.001$ & $6 \cdot 7$ \\
\hline Ex. & 0.87 & $<0.020$ & $6 \cdot 1$ & 0.87 & $<0.010$ & 53 \\
\hline \multirow{2}{*}{\multicolumn{7}{|c|}{$\mathrm{h}_{\text {MMS }}(n=22)$}} \\
\hline & & & & & & \\
\hline Rest & 0.79 & $<0.001$ & $8 \cdot 6$ & 0.72 & $<0.005$ & $10 \cdot 4$ \\
\hline Ex & 0.48 & NS & $9 \cdot 5$ & 0.50 & NS & 8.9 \\
\hline All & $0 \cdot 72$ & $<0.001$ & $8 \cdot 8$ & 0.68 & $<0-001$ & 9.9 \\
\hline \multicolumn{7}{|c|}{$\mathrm{h}_{\mathrm{TID}}(n=24)$} \\
\hline Rest & 0.76 & $<0.001$ & $12 \cdot 5$ & 0.75 & $<0.001$ & $12 \cdot 2$ \\
\hline Ex. & 0.25 & NS & 142 & 0.21 & NS & $15 \cdot 1$ \\
\hline All & 0.65 & $<0.001$ & $13 \cdot 3$ & 0.62 & $<0.005$ & $13 \cdot 3$ \\
\hline \multicolumn{7}{|c|}{$\mathrm{h}_{\mathrm{MMS}+\pi \mathrm{TD}}(n=24)$} \\
\hline Rest & 0.95 & $<0.001$ & 48 & 0.89 & $<0.001$ & $6 \cdot 8$ \\
\hline Ex. & 0.62 & NS & $11 \cdot 4$ & 0.55 & NS & $13 \cdot 0$ \\
\hline $\begin{array}{c}\text { All } \\
\text { LMM }\end{array}$ & $\begin{aligned} & 0 \cdot 88 \\
= & 24)\end{aligned}$ & $<0.001$ & $7 \cdot 0$ & 0.83 & $<0.001$ & $8 \cdot 2$ \\
\hline $\begin{array}{r}\text { LM } M_{L} \\
\text { Rest }\end{array}$ & $\begin{array}{r}=24) \\
0.91\end{array}$ & $<0.001$ & 88 & 0.90 & $<0.001$ & $9 \cdot 5$ \\
\hline Ex. & 0.92 & $<0.005$ & $9 \cdot 7$ & 0.94 & $<0-005$ & $7 \cdot 7$ \\
\hline All & 0.92 & $<0.001$ & $8 \cdot 9$ & 0.91 & $<0.001$ & 8.9 \\
\hline \multicolumn{7}{|c|}{$\operatorname{LMM}_{\text {MMS }}(n=22)$} \\
\hline Rest & 0.80 & $<0.001$ & $10 \cdot 5$ & 0.69 & $<0.005$ & $13 \cdot 7$ \\
\hline Ex. & 0.57 & NS & $19 \cdot 5$ & 0.51 & NS & $19 \cdot 8$ \\
\hline All & 0.72 & $<0.001$ & $15 \cdot 2$ & 0.66 & $<0.001$ & $17 \cdot 0$ \\
\hline \multicolumn{7}{|c|}{$\mathrm{LMM}_{\mathrm{TID}}(n=24)$} \\
\hline Rest & 0.84 & $<0.001$ & $14 \cdot 5$ & 0.83 & $<0 \cdot 001$ & $14 \cdot 0$ \\
\hline Ex & 0.47 & NS & $22 \cdot 5$ & 0.36 & NS & $24 \cdot 6$ \\
\hline All & 0.73 & $<0.001$ & $17 \cdot 7$ & 0.69 & $<0.001$ & $18 \cdot 4$ \\
\hline \multicolumn{7}{|c|}{$\mathrm{LMM}_{\mathrm{MMS}+\operatorname{TW}}(n=24)$} \\
\hline Rest & 0.95 & $<0.001$ & $7 \cdot 3$ & 0.92 & $<0-001$ & $8 \cdot 9$ \\
\hline Ex. & 0.80 & $<0.050$ & 14.9 & 0.80 & $<0-050$ & $15 \cdot 2$ \\
\hline All & 0.91 & $<0.001$ & $9 \cdot 6$ & 0.88 & $<0.001$ & 10.6 \\
\hline
\end{tabular}


Table 7 Datafrom the literature for comparison of LV wall thickness and muscle mass determunation with echocardiography and digital subtracton angiocardiography.

\begin{tabular}{|c|c|c|c|c|c|c|c|}
\hline Echocardiography & $n$ & $r$ & $\begin{array}{l}\text { SEE } \\
(\mathrm{mm})\end{array}$ & $\begin{array}{l}\text { SEE } \\
(\%)\end{array}$ & $\begin{array}{l}\text { Mean }_{\text {echo }} \\
(\mathrm{mm})\end{array}$ & $\begin{array}{l}\text { Meann } \\
(\mathrm{mm})\end{array}$ & $P$ \\
\hline \multicolumn{8}{|l|}{ LV wall thickness } \\
\hline Troy el al. ${ }^{\prime \prime \prime}$ & 24 & 0.89 & $1 \cdot 3$ & 14 & $8 \cdot 5$ & $9 \cdot 2$ & $<0.025$ \\
\hline Hahn et al. ${ }^{\mathrm{m}}$ & 18 & 029 & - & - & - & - & - \\
\hline Sjoegren el al. & 20 & 077 & $4 \cdot 0$ & 26 & $15 \cdot 4$ & $15 \cdot 3$ & NS \\
\hline Murray et al! $!^{[2]}$ & 21 & $0 \cdot 77$ & 1.9 & 21 & $8 \cdot 8$ & $9 \cdot 8$ & $<0.020$ \\
\hline LV muscle mass & & & $(\mathrm{g})$ & $(\%)$ & (g) & (g) & \\
\hline Troy et al & 24 & 0.88 & 49 & 20 & 214 & 246 & $<0.020$ \\
\hline Hahn et al. ${ }^{[20]}$ & 18 & 0.73 & - & - & - & - & - \\
\hline Sjoegren el al. ${ }^{[1]}$ & - & - & - & - & - & - & - \\
\hline Murray et $a^{122]}$ & 21 & $0 \cdot 83$ & 55 & 46 & 120 & 249 & $<0.001$ \\
\hline $\begin{array}{l}\text { Digital subtraction } \\
\text { anglocardiography }\end{array}$ & $n$ & $r$ & $\begin{array}{l}\mathrm{SEE} \\
(\mathrm{mm})\end{array}$ & $\begin{array}{l}\text { SEE } \\
(\%)\end{array}$ & $\begin{array}{l}\operatorname{Mean}_{\mathrm{DSA}} \\
(\mathrm{mm})\end{array}$ & $\begin{array}{l}\text { Mean }_{\text {sngio }} \\
(\mathrm{mm})\end{array}$ & $P$ \\
\hline \multicolumn{8}{|l|}{ LV wall thickness } \\
\hline Lauber et $a l^{[24]}$ & 20 & 0.74 & 16 & 16 & $10 \cdot 2$ & $11 \cdot 0$ & NS \\
\hline Own data (method 2) $\dagger$ & 24 & 081 & 0.7 & 9 & $7 \cdot 7$ & 89 & $<0.001$ \\
\hline LV muscle mass & & & (g) & $(\%)$ & (g) & (g) & \\
\hline Lauber et al. ${ }^{[24]}$ & 20 & 0.85 & 50 & 19 & 260 & 285 & NS \\
\hline Own data (method 2) + & 24 & 0.83 & 23 & 12 & 177 & 192 & $<0.001$ \\
\hline
\end{tabular}

* Systolic and diastolic data.

†Represent the mean of both observers for restung data

Abbreviations as in Tables 1 and 2. Conventional LV angiocardiography was used as the reference method for both echocardıography and digital subtraction angiocardiography.

determination under varying loading conditions with a change in heart size and wall thickness. Conventional LV angiocardiography was used as the reference method for wall-thickness and musclemass determination. The advantage of digital subtraction angiocardiography is related to the semi-invasive nature of the technique which allows evaluation of patients on an ambulatory basis and also during exercise. The high resolution of angiocardiography and the determination of the maximal outer border (not a tomographic section as with echocardiography, computer tomography or magnetic resonance) by angiographic techniques allow a more accurate determination of $\mathrm{LV}$ muscle mass due to the fact that LV geometry is obtained more exactly than with most other techniques. It is obvious that digital subtraction angiocardiography produces images which are similar to conventional angiocardiography. Thus, a comparison between these two techniques seems to be appropriate to test the validity of digital subtraction angiocardiography for LV wall-thickness and muscle-mass determination.
The present analysis shows that LV wall thickness and muscle mass can be determined accurately by digital subtraction angiocardiography (Tables 5 and 6) but there was a significant over- (method 1) or underestimation (method 2) when compared to conventional angiography. This over- or underestimation of LV wall thickness and muscle mass is explained by the fact that the Rackley technique (method 1) is a better approximation of true wall thickness because it is based on the measurements of multiple wall diameters, whereas method 2 (planimetry) is based on an 'area-length' method which tends to underestimate true wall thickness ${ }^{[13]}$. Method I slightly overestimated true angiographic wall thickness by $5-7 \%(P<0.02)$, whereas method 2 underestimated true angiographic wall thickness by $12-14 \%(P<0.001)$. Similar data were obtained at rest and during exercise.

The specific subtraction mode is especially important in digital subtraction angiocardiography for obtaining meaningful results of LV wall thickness and muscle mass. In a previous study ${ }^{(9)}$ it was demonstrated that a combined subtraction mode 
with mask mode (MMS) and time-interval difference (TID) subtraction for the determination of $L V$ volumes and ejection fraction showed the best correlations between conventional and digital subtraction angiocardiography. A similar trend was observed in the present analysis, because correlations for $L V$ wall thickness and muscle mass were best for the combined subtraction mode (Table 5) and worst for mask mode subtraction alone. Timeinterval difference subtraction was somewhat better due to its high spatial resolution and good contour recognition capabilities for fast-moving $L V$ regions (Table 5). Thus, the combined subtraction mode (MMS + TID) is recommended for the assessment of LV wall thickness and muscle mass by digital subtraction angiocardiography.

The standard error of estimate of the mean was larger for determination of LV muscle mass than wall thickness because the errors of measuring wall thickness and volume are added for calculation of LV muscle mass (Figs 3 and 4). Wall-thickness determination by method 1 (Rackley method) was somewhat less good with a larger standard error of estimate of the mean than method 2 (planimetry) probably due to the fact that method 2 reduces the measuring error by using wall thickness area rather than wall thickness diameter.

The interobserver comparison (Table 6) showed excellent results for $\mathrm{LV}$ wall thickness and muscle mass when conventional angiocardiography was used. The results for digital subtraction angiocardiography were less good than for conventional angiocardiography especially for data during exercise. The combined subtraction technique showed the best results with regard to interobserver variability; the standard error of estimate was smaller than $10 \%$ for data at rest, but larger than $10 \%$ for data during exercise.

When the present data are compared to results reported in the literature (Table 7) similar correlations are observed between conventional angiocardiography and digital subtraction angiocardiography. Most other authors, however, used either mask mode ${ }^{[\vartheta]}$ or time-interval difference ${ }^{[24]}$ subtraction but not a combined subtraction mode for $L V$ wall-thickness determination. This probably explains the slightly smaller standard error of estimate of the mean in our study than those reported by others, although the correlation coefficients were similar. It is generally accepted that a reliable technique for assessment of cardiac dimensions should be associated with a standard error of estimate of the mean smaller or equal to $10 \%$ of the mean of the reference technique; for example, when wall thickness is $10 \mathrm{~mm}$ and muscle mass $150 \mathrm{~g}$, the technique with a standard error of estimate of the mean of $10 \%$ measures wall thickness to be between 9 and $11 \mathrm{~mm}$ and muscle mass between 135 and $165 \mathrm{~g}$. In the present study a standard error of $10 \%$ or less was achieved for LV wall thickness, but a slightly larger standard error, namely $13 \%$ or less for LV muscle mass. However, most data reported in the literature (Table 7) do not fulfil this requirement, 1.e. a standard error of more than $10 \%$ is reported. When these data from the literature and ours are compared with data obtained by other imaging techniques, such as echocardiography, a considerably larger standard error is observed (14-26\% for wall thickness and $20-46 \%$ for muscle mass) than for digital subtraction angiocardiography.

Limitations of DSA for assessing LV wall thickness are related to misregistration of the subtraction mask and the iodinated frame which becomes especially important for mask-mode subtraction. Time-interval difference subtraction is almost insensitive to motion artifacts and produces a good contrast for the fast-moving ventricular wall but fails to detect local hypokinetic regions. Thus, a combination of both subtraction modes was used in the present study to optimize contour detection for the assessment of LV wall thickness. Another limitating factor of digital subtraction angiocardiography is related to the semi-invasive nature of the technique because a central venous catheter has to be placed for large volume injection with flow rates in the range of $12-18 \mathrm{ml} \mathrm{s}^{-1}$. Cineangiocardiography was used in the present study to guarantee high temporal (50 frames $\mathrm{s}^{-1}$ ) and spatial resolution. Most other authors ${ }^{[5.10-12]}$ have used videoangiocardiography, but temporal ( 25 frames $s^{-1}$ ) and spatial $(256 \times 256$ pixel) resolution of the video system might be a limiting factor especially under exercise conditions with high heart rates. Further developments in the near future might, however, provide a cineangiographic system which allows triggered radiation at end-diastole and end-systole to limit radiation exposure but guarantee highquality images.

Repeated contrast medium injections might be associated with alterations in basic hemodynamics and, therefore, affect the functional parameters of the left ventricle. This is not of great importance for assessing LV muscle mass, because this variable is not dependent on the actual loading conditions. The 'area-length' method was used for calculation of the LV short axis diameter according to the 
technique of Rackley et al..$^{[6]}$. This technique reduces the measuring error by calculating the short-axis diameter from the area and the long axis of the left ventricle $^{[13]}$. Furthermore, the Rackley technique assumes uniform wall thickness around the left ventricle which in a strict sense is not true. However, validation of the Rackley technique by autopsy ${ }^{16.25}$ showed excellent correlation between angiocardiography and direct measurements of LV mass. It is clear that this technique is not appropriate for calculation of LV muscle mass in the presence of myocardial infarction because of the thinning of $L V$ wall thickness in the infarcted area. However, the purpose of the present study was to compare digital subtraction and conventional angiocardiography for assessing LV wall thickness and muscle mass. It was not the purpose of this study to test the validity of the Rackley technique for estimating $\mathrm{LV}$ muscle mass in patients with coronary artery disease.

In summary, subtraction angiocardiography is a reliable tool for assessing LV wall thickness at rest and during supine bicycle exercise. Determination of LV muscle mass is less accurate than that of LV wall thickness due to the fact that the measuring error of LV wall thickness and volume are added. Possible drawbacks of digital subtraction angiocardiography are motion artifacts at high workloads and the hemodynamic alterations induced by contrast dye injections. Other imaging techniques provide reasonably good estimates of LV wall thickness and muscle mass with a slightly larger standard error of estimate than for digital subtraction angiocardiography, but most of these techniques do not allow assessment of LV wall thickness and muscle mass under exercise conditions. A combined subtraction mode using method 2 was shown to be the most reliable technique for assessing LV wall thickness by digital subtraction angiocardiography.

\section{References}

[1] Troy BL, Pombo J, Rackley CE. Measurement of left ventricular wall thickness and mass by echocardiography. Circulation 1972; 45: 602-11.

[2] Devereux RB, Casale PN, Essenberg RR, Miller DH, Klingfield $P$. Electrocardiographic detection of left ventricular hypertrophy using echocardiographic determination of left ventricular mass as the reference standard. J Am Coll Cardiol 1984; 3: 82-7.

[3] Miller SW, Dinsmore RE, Wittenberg J, Maturi RA, Powell WJ JR. Right and left ventricular volumes and wall measurements: determination by computed tomography in arrested canine hearts. Am J Roentgenol 1977; 129: 257-61.
[4] Florentine MS, Grosskreutz CL, Chang W, el al. Measurement of left ventricular mass in vivo using gated nuclear magnetic resonance imaging. J Am Coll Cardiol 1986; 8: 107-12.

[5] Radtke W, Buersch JH, Brennecke R, Hahne HJ, Heintzen PH. Assessment of left ventricular muscle volume by digital angiocardiography. Invest Radiol 1983; 18: 149-54.

[6] Rackley CE, Dodge HT, Coble YD, Hay RE. A method for determining left ventricular mass in man. Circulation 1964; 29: 666-71.

[7] Krayenbuehl HP, Hess OM, Schneider J, Turina M. Rückbildung der Herzhypertrophie bei Patienten mit operierten Aortenklappenfehlern. Z Kardiol 1985; 74 (Suppl 7): 145-52.

[8] Kennedy JW, Twiss RD, Blackmon JR, Merendino KA. Hemodynamic studies one year after homograft aortic valve replacement. Circulation 1968; 37 (Suppl II): $110-8$.

[9] Birchler B, Hess OM, Murakamı T, Niederer P, Anliker $M$, Krayenbuehl HP. Comparison of intravenous digital subtraction cineangiocardiography with conventional contrast ventriculography for the determination of the left ventricular volume at rest and during exercise. Eur Heart J 1985; 6: 497-509

[10] Brennecke R, Brown TK, Buersch J, Heintzen PH. Digital processing of videoangiocardiographic image series using a mini computer. In: Computers in cardology. St Louis, 1976: 255-60.

[11] Vas R, Diamond GA, Forrester JS, Whiting JS, Swan HJC. Computer enhancement of direct and venousinjected left ventricular contrast angiography. Am Heart J 1981; 102: 719-28.

[12] Lauber A, Fischbach T, Poelitz B, Schmiel FK, Spiller P, Loogen F. Digitale Subtraktionsangiographie. Genauigkeit der linksventrikulären Volumenbestimmung bei intravenöser Kontrastmittelinjektion. Z Kardiol 1983; $71: 262-7$.

[13] Sandler H, Dodge HT. Angiographic methods for determination of left ventricular geometry and volume. In: Mirsky I, Ghısta DN, Sandler H, eds. Cardiac mechanics. New York: Wiley, 1974: 141-70.

[14] Bland JM, Altman DG. Statistical methods for assessing agreement between two methods of clinical measurement. Lancet 1986; I: 307-10.

[15] Devereux RB, Reichek N. Left ventricular hypertrophy. Cardiovasc Rev Rep 1980; 1: 55-68.

[16] Krayenbuehl HP, Hess, OM, Schneider J, Turina $\mathbf{M}$. Physiologic or pathologic hypertrophy. Eur Heart J 1983; 4 (Suppl A): 29-34.

[17] Clark DG, McAnulty JH, Rahimtoola SH. Valve replacement in aortic insufficiency with left ventricular dysfunction. Circulation 1980; 61 411-21.

[18] Herreman F, Ameur A, de Vernejoul F, et al. Pre- and postoperative haemodynamic and cineangrographic assessment of left ventricular function in patients with aortic regurgitation. Am Heart J 1979; 98: 63-72.

[19] Fisher MR, von Schulthess GK, Higgins CB. Multiphasic cardiac magnetic resonance imaging: normal regional ventricular wall thickening. Am J Roentgenol 1985; 145: 27-30.

[20] Hahn B, Bohn I, Strauer BE. Funktionsbeurteilung des Herzens mittels zweidimensionaler Echokardiographie: vergleichende Untersunchunge zur Cineangiographie 
und Erstellung von Normalwerten für Erwachsene. $Z$ Kardiol 1982; 71: 445-51.

[21] Sjoegren AL, Hytoenen I, Frick MH Ultrasonk measurements of left ventricular wall thickness. Chest 1970; 57: 37-40.

[22] Murray JA, Johnston FW, Reid JM. Echocardiographic determination of left ventricular dimenston, volumes and performance. Am J Cardiol 1972, 30 252-7

[23] Sasayama S, Franklin D, Ross Jr J, Kemper WS, McKown D. Dynamic changes in left ventricular wall thickness and their use in analyzing cardiac function in the conscious dog: A study based on a modified ultrasonic technıque. Am J Cardıol 1976; 38: 870-9.
[24] Lauber A, Deetjen W, Jehle J, Poelitz B, Schmiel FK, Spiller P. Digitale Subtraktıonsangiographı: Genauigkeıt der Messung von linksventrikulären Wanddıcken und Wandvolumina bei intravenöser Kontrastmıttelinjektion Z Kardiol 1984; 73 257-63.

[25] Kennedy JW, Reichenbach DD, Baxley WA, Dodge HT. Left ventricular mass: a comparison of anglocardiographic measurements with autopsy weight. Am J Cardiol 1967, 19:221-3 